\title{
Enriquillo y la identidad colonial dominicana
}

\section{The Dominican Colonial ldentity}

\author{
Juan Carlos Flores Cornejo \\ Universidad Nacional \\ tua@hotmail.com
}

\section{Resumen}

Este trabajo analiza el texto Enriquillo, leyenda histórica dominicana de Manuel Jesús Galván desde la lógica de creación de identidades e historias locales; la forma en que contrastan con el imaginario de identidad colonial dominicana; la combinación de discursos culturales hegemónicos y subalternos, resultado de la creación de acto-espacios del discurso colonial. Se analizan, desde el mimetismo, algunos de los personajes de la novela y la manera en que sus identidades individuales se desarrollan paralelas a la creación de espacios de limitación centrífugos y centrípetos, expresados en la novela por la creación de identidades formadas o fragmentadas por el mito de la pacificación del nuevo mundo. A su vez, se aborda la manera en que lo centrípeto, lo multicultural y la alteridad juegan un papel preponderante dentro del texto.

Palabras clave: Mimetismo, colonialidad, identidad, alteridad, acto-espacio.

\section{Abstract}

This essay analyzes Enriquillo, leyenda histórica dominicana (Manuel Jesús Galván) from the local stories and identities creation; the way in which they are contrasted with the Dominican colonial identity; the combination of subaltern and hegemonic discourses resulting for the creation of act-spaces of the colonial discourse. Some of the characters are studied from the mimicry and the form their individual identities are developed following the creation of fragmented identities due to the new world's myth of pacification. Likewise, the way in which 
multiculturalism, alterity and centripety are developed in the text is addressed.

Keywords: Mimicry, coloniality, identity, alterity, act-space.

Explica Said (1989, p. 217) que los efectos de la colonización se extendieron mas allá de la conquista y fueron más agudos un vez que se lograron las independencias nacionales. Los resultados, enumerando unos cuantos, fueron la dependencia de las nuevas naciones a sistemas económicos foráneos, consecuentemente pobreza, subdesarrollo, patologías de poder y corrupción que "designated the colonized people who had freed themselves on one level but who remained victims of their past on another" (p. 207). Paralelo a lo anterior, entendemos que la conformación de una nación supone el establecimiento de una identidad que agrupe y homogenice aspectos tan disimiles como lo son la raza, diferencias sociales y religiosas. Similarmente, Barthes (1981) nos expone que la idea de nación, que considera ser de índole totalmente burguesa, "sirvió para excluir... sin perjuicio de rechazar los elementos que decrete alógenos" (p. 126).

Quizá esa sea la razón por la cual los proyectos de creación de estado nación en Latinoamérica, como en los demás países, han sido problemáticos. Así que a primera instancia la pregunta gira en torno a cómo los factores de conformación de identidad individual, grupal y nacionales transforman la idea de lo que entendemos como nación, esto es, ¿cómo se distingue lo que es de lo que no es? ¿lo que pertenece a lo que no? ¿lo que se es de lo que se pretende ser? En todas las respuestas, tal y como lo han argumentado críticos tan disimiles como Sollors, Fanon, Bhabha, Spivak, Said y demás, la percepción y construcción de identidades nacionales o individuales reside en la idea de la diferencia y la otredad: Lo que me hace ser lo que soy en oposición a otro ajeno a mí. La relación, y en definitiva la definición, se hace a partir de la comparación con otro, frecuentemente relegado a un segundo plano y la mayoría de las veces determinado solamente para establecer lo que no se es.

Este trabajo analiza el texto Enriquillo, leyenda histórica dominicana de Manuel Jesús Galván desde la lógica de creación de identidades -actos espacios según Manzo-Robledo (2008) -y la forma en que contrastan con el imaginario de identidad colonial dominicana a partir de la combinación de discursos culturales hegemónicos y subalternos, resultado de la creación de acto-espacios provenientes del discurso colonial. El concepto de mimetismo, que entendemos como la imitación desde la diferencia en el discurso colonial, que favorece la rearticulación de la realidad mediante la contraposición de dos perspectivas 
antagónicas de la misma, resultado en un deseo que repite y re-articula la realidad a partir del mimetismo (Bhabha, 1994, p. 90) Asimismo, el mimetismo nos sirve como punto de partida para el análisis de algunos de los personajes de la novela, a saber: el gobernador Frey Nicolas de Obando, el colonizador Diego Velásquez, Fray Bartolomé de las Casas, el indio Tamayo y, por supuesto, Enriquillo; la manera en que sus identidades individuales se desarrollan paralelas a la creación de espacios de limitación centrífugos y centrípetos, expresados en la novela por la creación de identidades formadas o fragmentadas por el mito de la pacificación del nuevo mundo y su triada cuyos objetivos fundamentales, según explica Manzo (2008, p. 9), son la obtención de oro y riquezas, la gloria personal y del soberano en función, y la gloria del Dios de la religión judeo-cristiana. A su vez, se aborda la manera en que lo centrípeto (en relación con la teoría del acto- espacio) se invierte en el caso de Fray Bartolomé de las Casas debido a que para él, como se describe en la novela, Dios es el centro, en un segundo plano se encuentra el poder que viene del Rey o su representante y en el tercer plano el "yo".

La identificación por diferencia funciona bajo una formula directa, simple y determinista, pues tal y como distingue Said "yet the most striking thing about "otherness" and "difference" is, as with all general terms, how profoundly conditioned they are by their historical and worldly context" (1989, p. 213). La propuesta de Said nos lleva mas allá de la simple y brusca comparación para buscar diferencias y nos ubica en los condicionamientos de tipo histórico y "mundano" que perfilan la propuesta. De manera que la construcción de identidad se operacionaliza a niveles tan sencillos y tan complejos como lo son las situaciones personales, el devenir histórico, y todos los contextos en los cuales se podría presentar, lista que sería interminable de enumerar según la proposición de Said. Resultado de esta maraña de circunstancias y factores que centralizan los patrones fundadores y creadores de identidad, tenemos el papel de la literatura como elemento que guía y forma las expresiones nacionales, para luego conducirnos por el camino de la homogenización histórica personal y nacional. La novela de Galván no escapa de esta máxima, e irrumpe en exigua tradición literaria dominicana para convertirse en "un mito nacional capaz de ser adoptado tanto por conservadores como por reformista" (Sommers, 1983 , p.117).

Para Imbert-Anderson (1950), la aparición de textos y escritores que se basaran y desarrollaran las "leyendas en que las desventuras del indio son ocasión para afirmaciones patrióticas". También argumenta que en el caso particular de la Republica Dominicana, se perdió la raza india como resultado de la influencia política española, resultando en la transformación de la raza como un símbolo de resistencia, sublevación y del espíritu de libertad de los dominicanos que se 
enfrentaban a España (pp. 207-218). Anderson también expone que el indigenismo obedeció a un móvil de restauración nacional, pues según continua explicando, "Galván, en medio de este florecimiento comenzó su novela idealizando también a los indios".

Para entender el proyecto de Galván se requiere entender la moral colonial -burguesa por antonomasia al ser trasladada al nuevo mundo donde el blanco siempre gozaría de una posición de poder sobre un otro trasformado en subalternoy la relación que existe con respecto a su mundo, su horizonte de expectativas o su acto-espacios que definen, delimitan y circunscriben a los actantes (Manzo, 2008, p. 52). El fenómeno lo explica Barthes en los siguientes términos: "El pequeño burgués es un hombre impotente para imaginar lo otro. Si lo otro se presenta a su vista, el pequeño burgués se enceguece, lo ignora y lo niega, o bien lo transforma en él mismo... En estos casos, aparece una figura de auxilio: el exotismo. Lo otro deviene puro objeto, espectáculo, guiñol: relegado a los confines de la humanidad, ya no atenta contra la propia seguridad (1981, p. 135). Es precisamente lo que sucede con el relato de Galván que se estructura en diferentes historias e hilos de narración que perpetuán el dominio español sobre el nuevo mundo colonizado, justificado a partir de recreación cíclica de la triada que Manzo $(2008$, p. 9) identifica como el yo, Rey y Dios.

\section{Sobre los personajes: Ovando}

$\mathrm{Si}$ el acto-espacio se define por factores endógenos y exógenos, y estos dos conjuntos definen los límites de lo que finalmente es válido hacer (Manzo 2008, p. 11), se puede afirmar entonces que este hecho justifica el proceder de los personajes representativos de la conquista pues todos sus atropellos se dan por el deseo de favorecer primeramente al yo para lograr gloria y poder, luego al Rey que es quien gobierna la nación y para el que la conquista de Nuevos mundos refleja una victoria representativa y, por supuesto, a Dios que es la excusa con la que estos se apropian de todo, volviendo así al punto de inicio y convirtiéndose este en un círculo inacabable( Manzo, 2008, pp. 9-14). Veremos entonces dentro de la novela algunos personajes medulares en la historia en donde este círculo es claro y evidente. Para dar inicio a este recuento es preciso analizar al primer gobernador de la Isla Española.

Encarna Frey Nicolás de Ovando una de las figuras de la conquista más hambrientas de poder y riqueza. Los actos cometidos por este ser, quien es depositario de la 
absoluta confianza de los Reyes católicos, y a quien se le ha asignado el gobierno de la Isla Española, son quizás el origen de la "civilización" del Nuevo Mundo, los cuales inician con la ejecución sangrienta y despiadada de todos los caciques del reino de Jaragua como se evidencia en las primeras páginas de la novela, donde se explica que "los sucesos cuya narración va a llenar las hojas de este pobre libro tienen origen y raíz en la espantosa tragedia de la Jaragua. Fuerza no es fiar la consideración en la poco simpática figura del adusto comendador Frey Nicolás de Ovando autor de la referida catástrofe" (Galván, 1909, p. 8). Es así como Galván representa el inicio de la sumisión indígena en la isla ante el dominio español. La estrategia narrativa nos conduce a lo que Anderson nos previene al ingresar en las primeras páginas del Enriquillo pues para el crítico, Galván," en esa primera pagina se ha dejado arrastrar por una simpatía romántica" (hacia lo indígena), "pero más adelante nos advierte que en realidad está de parte de la civilización europea" (1950, p. 219). El gobernador encarna el principio del mimetismo. Primero se identifica con el otro y se compadece para luego tratar de perfilar el comportamiento de los indios bajo patrones peninsulares.

En repetidas ocasiones en el texto se hace alusión a las atrocidades y atropellos del gobernador para con los naturales de la isla. Una de las situaciones más claras se describe de la siguiente manera: "La administración de Ovando había sido despótica y cruel para con la población indígena, que decrecía rápidamente al peso de los malos tratamientos" (Galván 1909, p. 80), sin embargo, existe una clara intensión del narrador por minimizar el efecto de sus fechorías utilizando en ocasiones adjetivos generosos para con el mismo, en el capítulo décimo de la primera parte podemos ver claramente este recurso, cuando el narrador suaviza el mal producido por Ovando y justifica: "El buen comendador creyó sin duda desagraviar la Majestad Divina y descargar su conciencia del crimen de Jaragua, echando los cimientos de una iglesia y convento de frailes Franciscanos, al mismo tiempo que colocaba la primera piedra de la casa municipal de la futura villa" (Galván, 1909, p. 42). El narrador le llama buen comendador aún cuando ya ha narrado que el mismo ha sido el autor de la masacre en Jaragua. Podemos notar a través de la misma cita la evidencia de que el acto-espacio individual del señor comendador está delimitado por su acto espacio-social al mostrar como preponderante la construcción de edificios de gobiernos y religiosos, es decir, el yo se siente redimido de sus culpas y libera su conciencia al rendirles homenaje a su rey y a Dios mismo. La redención trabaja en dos aspectos básicos que giran en torno al acto-espacio del comendador y la mimetismo esto es, la imitación de lo ibérico, en todos sus aspectos, pero para el personaje principalmente mediante la repetición de ciudades españolas en el nuevo mundo. 
Correspondientemente, si se analiza a Ovando desde la mimetismo, que podemos definir como la reproducción de algo a partir de la diferencia, vemos claramente como el desarrollo de la isla está motivado por el deseo de crear una ciudad llena de comodidades y lo más parecida posible a la Península Ibérica que viene a ser el referente, tal y como se muestra en la siguiente cita:

Los seis años de paz tiránica que Ovando llevaba en el gobierno habían elevado la isla Española al apogeo de su grandeza; los brazos de los indios (...) habían convertido la humilde nereida del Ozama en una hermosa ciudad, provista de edificios elegantes y vistosos... (Galván 1909, p. 104) .

Ovando necesita instalar iglesias, construir calles, casas y edificios encantadores para reproducir su realidad conocida pero no le es posible sin borrar lo que la hace la diferencia: su gente, los indios, su sistema de vida. De manera que debe primero matar a sus "naturales" y borrar toda figura de poder, debe mutilar sus creencias y de este modo instalarles un Dios nuevo; uno que necesita a un rey y a un gobernador para llegar a ellos, repitiendo y perpetuando su acto-espacio en los habitantes y en la isla.

\section{Diego Velásquez}

Son mencionados en la obra varios colonos importantes pero es posible que uno de los más representativos sea Diego Velásquez, quien es uno de los tenientes del gobernador Ovando y es además quien lleva el mérito de darle muerte al cacique Guaroa y Hatuey. Es pertinente tomarlo en cuenta porque comparte ciertos aspectos de los hemos hablado anteriormente pero existe en él una fluctuación del acto espacio pues en la ciudad es obediente a su gobernador y no desea agraviarle, sin embargo, el narrador expone que en el campo de batalla surgen sentimientos de caridad y benevolencia. Manzo (2008, p. 8-9) explica lo anterior al definir la existencia de diferentes fuerzas que permiten o previenen el actuar del actante o manejador del acto espacio. Para Manzo, coincidiendo con Lukács (1965), la voluntad del personaje le permite rebasar los cercos a las cuales se encuentra circunscrito y expandir el radio de acción, así como la circunferencia de sus acto-espacios.

Velázquez se construye entonces como la antítesis del colono estándar al obedecer la religión y a la política sólo en ocasiones; él obedece, en la mayoría de los casos a su instinto. Quizá se pueda explicar desde la lógica de la transformación del Kurtz de Joseph Conrad al permanecer demasiado tiempo en la selva. No obstante, al respecto expone Altman (2007, p. 220) que Galván justifica el proyecto 
colonial con un paralelismo entre la "leyenda negra" de soberbia, ignorancia, egoísmo, intrigas, con la "leyenda blanca" que permite las vejaciones españoles por medio de personajes filántropos rectos abnegados y exaltadamente cristianos. La siguiente cita ejemplifica lo anterior:

Diego Velásquez no era un malvado: impresionable, como todos los de su raza; imbuido en las falsas ideas religiosas y políticas de su tiempo, seguía el impulso fatal que movía a todos los conquistadores, queriendo someter a fuego y sangre los cuerpos y las almas de los desgraciados indios (Galván 1909, p. 47).

Este personaje que, al igual que todas las figuras de la colonización, fue el responsable de matanzas, violaciones y demás atropellos, es presentado por el narrador como noble, generoso y no se concibe dentro de él la maldad sino hasta el momento en que regresa a la selva. Ahí es capaz de someter a hombres y mujeres inocentes a las peores vejaciones, no obstante, sus acciones tienen un justificante; no responden a su deseo de servir a un Dios o a un gobernador sino al instinto de una raza "superior" que tiene el derecho de apropiarse del otro. En este caso el acto-espacio privado es mayor al público pues tal y como apunta Manzo no necesariamente el espacio privado debe ser expuesto al escrutinio externo, pues su poseedor es quien lo regula $(2008$, p. 7).

En oposición a lo anterior, se muestra, en el capítulo XIV de la primera parte de la obra, cómo Velásquez sube a la montaña en busca de Guaroa por orden del gobernador, "Diego Velásquez recibió la terrible orden del Gobernador cuando menos lo esperaba. Inmensa pesadumbre embargó su ánimo al ver que había incurrido en el enojo de su jefe; y atento solo a desagraviarle, puso en pie a su gente... (Galván 1909, p. 56)," pero su pesar no corresponde al mandato sino al agravio cometido a su gobernador a no haber aniquilado aún al jefe de los indios que no se habían sometido. Queda demostrado entonces que el narrador lo que nos expone es una fluctuación de el acto-espacio privado del personaje.

En la relación de la muerte de Guaroa, el narrador nos deja claro que Velásquez es un espectador; sus soldados están acabando con todos los indios que permanecen con el cacique, como lo demuestra la siguiente cita, "la sangre de las víctimas enrojece el suelo: el incendio no tarda en asociarse a la obra de exterminio, y las pajizas cabañas, convertidas en hogueras, abrasan los cuerpos de los indios" (Galván, 1909, p. 58). No es sino hasta que percibe la resistencia que opone el indio que decide intervenir, pero es este momento como en otros que el narrador nos imprime un sentimiento de respeto hacia el español que decide 
salvar al indio: "Desde lejos había visto al denotado combatiente defender su vida del modo heroico que se ha dicho; y su índole generosa volvió a preponderar, inspirándole el deseo de salvar aquel valiente" (Galván, 1909, p. 58). Claro está que dicha salvación corresponde a librarlo de la muerte, no de la mutilación de su existencia como tal, pues intentan apresarlo justamente por querer permanecer lejos del dominio español. Al permanecer el indio inamovible en su posición es sin mayor remedio sacrificado. Es aquí donde el narrador vuelve a utilizar adjetivos que demuestran un alma generosa y exenta de maldad. Nos expone a un español que intentó a toda costa evitar el sacrificio de un indio, pero al no lograrlo se expone a la debilidad más grande de su masculinidad: el llanto. Las justificaciones continúan en la obra y se nos explica que "El caudillo español, movido a respetuosa compasión ante aquel inmerecido infortunio, derramó una lágrima sincera sobre el cadáver del jefe indio..." (Galván, 1909, p. 58). Implícitamente el narrador nos dice que el deseo de salvar a este indio obedece a que este tenía una característica fundamental: peleaba con el valor y el coraje que lo hubiera hecho un "civilizado" y esto lo hacía merecedor del perdón de su oponente. Es más podríamos atrevernos a decir que Velásquez decide combatir él mismo contra Guaroa porque es el único que merece que desenfunde su espada, pues es en él quien percibe características similares a las suyas.

\section{Fray Bartolomé de las Casas}

Según Anderson (1950, p. 213), la novela histórica del siglo diecinueve buscaba nuevas formas de relacionarse con el pasado, similar a lo que vendría e exponer Benjamín en el siglo veinte. Según el crítico propone "el novelista del siglo XIX -el siglo de la Historia- enriqueció pues el viejo arte de contar con un nuevo arte de comprender el pasado". Para Anderson, la novela de Galván utiliza dos estrategias de acercamiento a la historia que tienden más hacia la veracidad, sacrificando muchas veces lo estético del relato. La novela no deja de ser una referencia histórica muy a pesar de la ficcionalización de varios de sus personajes y las diferentes estrategias discursivas que emplea Galván para amarrar el hilo temático y lo narrativo.

Analicemos ahora la figura de Bartolomé de las Casas dentro de la novela, la cual como ya se dijo, corresponde al género llamado novela histórica, pues es importante comprender que tal y como lo expone Sommer:

El lector que simpatiza con la novela alaba lo que erróneamente considera fidelidad histórica, mientras que sus detractores, por el contrario, consideran 
embarazosa su falsificación de los hechos. Pero ninguno, que yo sepa ha aplaudido a esta misma falsificación que ha creado un mito nacional capaz de ser adoptado tanto por conservadores como por reformista (1983, p. 117).

En el libro de Galván se afirma que fray Bartolomé recibió las órdenes sacerdotales en el año 1510, hecho que contradice Sommer cuando afirma que fue solo “... hasta 1515 que se convirtió en paladín del bien y protector de la población india en extinción, como su propia crónica revela, tras haberse beneficiado de su explotación" (1983, p. 125). Esta afirmación nos revela una realidad que Galván sabe disimular muy bien, que es el hecho de que de las Casas es un español que ha sido beneficiario de la conquista, que reprende el genocidio (conquista) desde la brutalidad pero no desde la obligación del indio a ser sumiso y obediente. En todo momento solicita a los indios doblegar su espíritu desde la doctrina judeocristiana utilizando el recurso del perdón a nuestros ofensores.

Ante este hecho Anderson apunta que Galván convirtió al Padre Las Casas en el eje doctrinario de su novela; siguió sus escritos al pie de la letra -y a veces textualmente-. Pero Galván no interpretó la prédica de Las Casas como una prueba de la bajeza moral de España, sino como un noble ejemplo que España ofreció al mundo. Fray Bartolome de Las Casas, después de todo, era español; y la fuerza de sus invectivas redime a España (1950, p. 219). Sobre este mismo punto Sommer expone que el propósito de la novela de Galván no es la protección de los indios; en vez de ello, usa como motivo aparente de la narración el amor cristiano del apóstol para legitimar un código legal más racional que generoso; código que Oviedo comprendió que era necesario para mantener el orden bajo la supremacía española (1983, p. 121).

Vayamos a puntos concretos dentro de la novela. Bartolomé profesa el amor de Dios y así los indios como sus siervos al Señor; deben mantenerse mansos de corazón. Según la novela, el interés que lo mueve a estar pendiente de todo lo concerniente a la colonización es el afán por glorificar a Dios. Bartolomé se nos muestra como un intercesor en la mayoría de las ocasiones, de modo que, en cuanta escena aparece es para defender una causa o a un individuo, toda vez que esta sea del agrado de nuestro creador. Con sus comentarios siempre llama a los corazones a moverse a clemencia; sin embargo, cuando se trata de los indios y sobre todo de Enriquillo, su mensaje va dirigido a la mansedumbre. Tal es el caso cuando Enriquillo se niega a acompañar a Diego Velásquez a ofrecer una serenata para María de Cuellar, debido a que se encuentra muy cercana la muerte de su tía Higuemota. Velásquez enfurece terriblemente y lo llama ingrato y, a pesar de que Enriquillo se muestra sumiso en la escena, la recomendación que le hace el 
padre De las Casas a Enriquillo, una vez que ha conversado de los hechos con el teniente, es que se mantenga sumiso.

Como se remite en la obra: "es menester que hagas por cumplir de buen talante tus deberes con los señores a Virreyes, con tu padrino, con todos, mientras estés por aquí. Irás a menudo a ver a Mencía; no le pongas a nadie mala cara; sé prudente y sufrido como te he recomendado" (Galván, 1909, p. 186). Se deja ver claramente que aunque Enrique no es sirviente de la casa de los virreyes y se declara libre en todo momento, debe obediencia a todos a quienes debe esa condición y que el padre juega con la orfandad del muchacho y el cariño que se siente hacia su persona para minimizar los impulsos de rebelión y mantener su corazón sumiso como un siervo del señor.

Otro ejemplo claro de esta intención es el llamado que hace Bartolomé a Enriquillo cuando este le comenta que Diego Valenzuela daba muestras de no verle de buen modo por mostrarse celoso por el cariño que don Francisco, su padre, siente por el caciquillo: "tal vez; -respondió pensativo las Casas-; pero tú sigue siendo bueno, cumple con tus deberes; sé humilde y manso de corazón, y deja lo demás a Dios" (Galván, 1909, p. 248).

Es claro que la recomendación no hubiese sido la misma si se tratara de un "justo" español y de hecho, no se muestra en el libro que Bartolomé hiciera un llamado de atención al joven Valenzuela, cuando nada se lo impedía pues Fray Bartolomé se atrevía hasta hacerse escuchar por el rey, a fuerza, si era asunto que realmente le interesara. Y peor aún, una vez que Diego Valenzuela ha cometido cuanto abuso y atropello a querido contra Enriquillo, hasta ultrajar a su esposa y robarle los bienes que por derecho tenía ganados así como el dinero de Mencía, basta con un arrepentimiento -que en realidad surge del terror a que Tamayo tome la justicia en sus manos y olvide el perdón que Enrique le ha dado- para que el sacerdote le asigne su perdón pues, al igual que en la parábola del hijo pródigo, este hombre merece la redención por el reconocimiento de sus culpas, como se demuestra en el texto:

Muy complacido escuchó las Casas estas manifestaciones del contrito Valenzuela, y no solamente lo exhortó a perseverar en sus laudables propósitos, sino que se ofreció a ayudarle en la ejecución de ellos; y empleando su genial actividad, desde el mismo día trabajó tanto, que al cabo de tres días (...) hizo salir de la cárcel a Valenzuela (Galván, 1909, p. 445).

No podemos dejar de hablar sobre don Bartolomé, sin antes volver al punto de partida: el mimetismo y el acto-espacio. ¿Cómo se dan estos dos supuestos en este personaje? Siendo muy concretos y precisos, la figura de las Casas en 
la novela representa una inversión del acto-espacio y la supresión de los dos primeros objetivos de la triada pues para él, en la novela, lo realmente importante, tal y como se expuso anteriormente, es la glorificación del Dios de la religión judeo-cristiana.

\section{Enriquillo}

La forma en que Enrique es percibido por lo españoles es ambigua y poco clara, de hecho, si nos remontamos al episodio de la firma del tratado de paz y la posterior asignación del título de don de parte de los españoles, es claro que Enrique y su identidad es escindida entre lo taino, lo español y otro que no se identifica con ninguno de los dos. La labor de cristianización que el fraile De las Casas focalizo en Enrique, rinden sus frutos al reducir los embates de rebelión de Enrique mediante el discurso de bondad y liberación de la doctrina Judeocristiana. Con respecto a la identidad escindida de Enrique, vale la pena citar a Altman, quien replica:

Spanish officials readily found parallels between the growing threat from rebellious African slaves and Enrique's revolt. Audiencia judge Licenciado Cerrato wrote to the crown in September 1544 that "it would be preferable that there weren't so many ladino slaves born in this country, because they are a bad nation, very daring and badly inclined, and they are the ones who mutiny and make themselves captains. The bozales aren't like this. The same was seen in the business of Enrique (2007, p. 611).

Aún cuando Enrique usa la máscara blanca que Fanon (1967) acusa, su diferencia radica en la puntos de concordancia con los modelos ibéricos, de manera que es igual pero diferente, tal y como al respecto Bhabha (1994, p. 91) propone al explicar:

Mimicry, as the metonymy of presence is, indeed, such an erratic, eccentric strategy of authority in colonial discourse. Mimicry does not merely destroy narcissistic authority through the repetitious slippage of difference and desire. It is the process of the fixation of the colonial as a form of crossclassificatory, discriminatory knowledge within an interdictory discourse, and therefore necessarily raises the question of the authorization of colonial representations, a question of authority that goes beyond the subject's lack of priority (castration) to a historical crisis in the conceptuality of colonial man as an object of regulatory power, as the subject of racial, cultural, national representation. 
En el caso de Enrique, su esfuerzo por imitar los actos espacios promovidos y postulados por la autoridad colonial resultan en el cuestionamiento de la autoridad colonial y la identidad propia, sobreviviendo a esto la autoridad religiosa tan bien pregonada por el Fray en la identidad de Enrique. Pues tal y como lo apunta Bhabha (1984), la desautorización viene de la imitación fetichista de las múltiples formas de autoridad.

Podemos afirmar entonces que la Metaotredad o mimetismo se dan en Enrique al imitar y pretender bautizar a los niños. Esto supone un regreso a la máscara blanca, concordando con la creación de nuevos espacios coloniales o el retorno a los actoespacios de antaño. Coincide con las observaciones de Fanon, Bhabha y Manzo al respecto. De hecho, la insurrección de Enrique supone la creación de nuevos espacios de desarrollo y la inversión de otros, aspecto que también ocurre con De las Casas y su relación con los acto-espacios. La inversión de los acto-espacios desestabiliza los patrones culturales y resulta en movimientos centrípetos.

Asimismo, para Las Casas dios se ubicaría en el primer círculo, el segundo lo ocuparía, de existir, el rey, y el tercero es el personal, que en el caso del fraile, se remitiría a hacer justicia a los indios pues la vida sacerdotal supone la nulidad del yo. De hecho, una de las razones que tuvo Fray Bartolomé para escribir su relato de las indias fue el de "castigar con el peso de la historia "a aquellos que no se entregaran a los mandatos divinos, cristianos y de supuesta humanidad que el profesaba. La otredad representa en la novela el choque de los diferentes actos espacios delimitados por el de los otros en posiciones de poder.

Concluimos este trabajo con una cita del texto de Galván que encierra el sentir de la colonia y al mismo tiempo describe de la forma más sencilla el tema desarrollado: "La civilización europea, que había arrebatado a aquellos infelices a su nativa inocencia, los devolvía a las selvas con nociones que los hacían aptos para la libertad, por el trabajo y la industria" (1909, p. 454).

\section{Referencias}

Anderson-Imbert, E., (1950). El telar de una novela histórica: "Enriquillo”, De Galván. Revista Iberoamericana (15) 30, 213-229.

Altman, I. (2007). The Revolt of Enriquillo and the Historiography of Early Spanish America. The Americas (63) 4, 587-614. 
Barthes, R. (1981). Mitologías. México: Siglo XXI.

Bhabha, H. (1994). The Location of Culture. London: Routledge.

Fanon, F. (1967). Black Skin, White Masks. New York: Grove Press.

Galván, M. (1909) Enriquillo: Leyenda histórica Dominicana (1503-1533). Barcelona: J. Cunill.

Goldmann, L. (1975). Para una sociología de la Novela. Madrid: Ayuso.

Lukács, G. (1966). Teoría de la Novela. Buenos Aires: Ediciones Siglo Veinte.

Manzo-Robledo F. (2008). El discurso de la Dominación: casos coloniales. México: Libros para todos.

Said, E. (1989). Representing the Colonized: Anthropology's Interlocutors. Critical Inquiry. 15.2: 205-225.

Sollors, W. (1988). The Invention of Ethnicity. New York: Oxford University Press.

Sommer, D. (1983). El Otro Enriquillo. Revista De Crítica Literaria Latinoamericana (9)17, 117-145.

Spivak, G. (1999). A Critique of Postcolonial Reason: Toward a History of the Vanishing Present. Cambridge, Mass: Harvard University Press. 